\title{
Analysis of the double occlusion which provides four pressure gradients
}

\author{
T.S. Hakim, K. Sugimori, L. Ferrario
}

Analysis of the double occlusion which provides four pressure gradients. T.S. Hakim, K. Sugimori, L. Ferrario. CERS Journals Ltd 1996.

ABSTRACT: The arterial, double and venous occlusions are used to partition pulmonary vascular resistance into four segments. In this study, we tested whether the same can be accomplished from one double occlusion.

In an isolated canine lung left lower lobe perfused with blood (flow rate $=500$ $\left.\mathrm{mL} \cdot \mathrm{min}^{-1}\right)$, the pulmonary arterial and venous pressures $(P$ and $P \mathrm{v}$, respectively) were measured directly. Arterial, double, and venous occlusions were performed and analysed as usual (Method 1) to measure pressures in small arteries and small veins $\left(\boldsymbol{P}_{\mathrm{a}}{ }^{\prime}\right.$ and $\boldsymbol{P}_{\mathrm{v}}$ ', respectively) and capillary pressure $(\boldsymbol{P})$. Alternatively, one double occlusion was analysed (Method 2 ), not only for $P_{\mathrm{a}}, \boldsymbol{P}_{\mathrm{v}}$ and $P \mathrm{c}$, but also as independent arterial and venous occlusions to measure $\boldsymbol{P}^{\prime}$ ' and $\boldsymbol{P}_{\mathrm{v}}{ }^{\prime}$.

Method 1 yielded $P \mathrm{a}, P_{\mathrm{a}}, P_{\mathrm{c}}, P_{\mathrm{v}}$, and $P_{\mathrm{v}}$ (Baseline) of 14.2 $\pm 1.7,10.8 \pm 1.6,8.9 \pm 1.9$, $7.3 \pm 1.5$ and $1.3 \pm 0.6 \mathrm{mmHg}$, respectively $(1 \mathrm{mmHg}=0.133 \mathrm{kPa})$. Method 2 yielded values for the same five pressures equal to $14.7 \pm 2.1,11.0 \pm 2.2,8.9 \pm 1.9,7.3 \pm 1.3$ and $1.3 \pm 0.6 \mathrm{mmHg}$, respectively. There was no significant difference in the pressure profile obtained using the two methods, nor were there differences during hypoxia and angiotensin infusion.

These results suggest that a more thorough analysis of the double occlusion can provide the same information about distribution of vascular resistance as provided by a combination of the three occlusions. The advantage of the new approach is that fewer occlusions are needed and resistance distribution can be assessed during a transient response. Because all pressures are derived from one occlusion, the pressures would be more accurate relative to each other. Eur Respir J., 1996, 9, 2578-2583.

The arterial and venous occlusion technique [1-3] allows partitioning of the pulmonary vasculature into three segments (arterial, middle and venous), while the double occlusion technique has been used to partition the vasculature into two segments upstream and downstream from a mid-capillary point [4]. The double occlusion technique, however, is not used to determine whether changes in resistance occur within small or large vessels. By combining the arterial, double and venous occlusion techniques, it is possible to partition the vasculature into four segments, and determine whether the site of constriction is in small or in large arteries or veins $[2,5]$. In this study, we show how the double occlusion can be analysed to provide four pressure gradients without performing arterial or venous occlusions independently. Thus, by performing one double occlusion manoeuvre lasting 3-4 s it would be possible to measure resistance of four vascular segments. This new approach has the advantage of being able to partition the vasculature into four segments when the vascular resistance is not in a steady-state.

\section{Materials and methods}

\section{Isolated lung preparation}

Ten mongrel dogs of either sex, weighing 20.3 \pm 3.5 (SD) $\mathrm{kg}$, were anaesthetized with sodium pentobarbital
(30 $\mathrm{mg} \cdot \mathrm{kg}^{-1}$ body weight), intubated and ventilated mechanically (Harvard Animal Ventilator). Following administration of heparin $\left(700 \mathrm{U} \cdot \mathrm{kg}^{-1}\right)$, the animals were exsanguinated via a catheter in the carotid artery. The procedure for perfusing the left lower lobe in situ has been described previously [1-3]. The left upper and middle lobes were tied-off and excised through a left thoracotomy. Cannulae were placed in the left lower lobe artery and vein. The arterial and venous cannulae were connected to a perfusion system. The recirculating perfusion system was filled with autologous blood (400 $\mathrm{mL}$, haematocrit (Hct) 40\%), and consisted of a reservoir, a pump (Masterflex 7015), and a filter, which also acted as a bubble trap and as a damper. Twelve milligrams of indomethacin in sodium bicarbonate (Sigma Chemical Co.) was mixed slowly into the reservoir prior to initiation of the perfusion. The lobe was perfused with blood $\left(400-600 \mathrm{~mL} \cdot \mathrm{min}^{-1}\right)$ from the reservoir, and the blood was allowed to drain back passively into the reservoir.

The blood flow rate $\left(Q^{\prime} \mathrm{t}\right)$ through the lobe was initially adjusted to provide an arterial pressure of 10 $15 \mathrm{mmHg}$. Venous pressure was set at $1-2 \mathrm{mmHg}$ by adjusting the level of the reservoir. The reservoir was immersed in a waterbath to maintain blood temperature at $37^{\circ} \mathrm{C}$. The pulmonary arterial and venous pressures, $P$ a and $P$ v, respectively, were measured from 
side-ports in the cannulae using two pressure transducers (PdI23B) relative to the top of the lobe, and recorded on an 8-channel recorder (Hewlett-Packard 8261). The lobe was ventilated with a gas mixture of $5 \% \mathrm{CO}_{2}$, $35 \% \mathrm{O}_{2}$, and $60 \% \mathrm{~N}_{2}$. The airway pressure was also monitored from a side-port in the tracheal tube. Endexpiratory pressure was set at $1-2 \mathrm{mmHg}$ and inspiratory pressure was kept below $10 \mathrm{mmHg}$ by adjusting the tidal volume. All measurements reported in this study were obtained with the ventilator turned off in expiration and the lungs were in zone 3 conditions. These ventilatory settings provided a carbon dioxide tension $\left(P_{\mathrm{CO}_{2}}\right)=4.7 \pm 0.3 \mathrm{kPa}(35.6 \pm 2.3 \mathrm{mmHg})$, oxygen tension $\left(\mathrm{PO}_{2}\right) 28.6 \pm 4.1 \mathrm{kPa}(215 \pm 31 \mathrm{mmHg})$, and $\mathrm{pH} 7.37 \pm$ $0.03(\mathrm{SD})$ in the blood. During hypoxic gas breathing $\left(5 \% \mathrm{CO}_{2}, 3 \% \mathrm{O}_{2}\right.$, and $\left.92 \% \mathrm{~N}_{2}\right)$, these values were $4.6 \pm 1.0 \mathrm{kPa}(34.7 \pm 7.4 \mathrm{mmHg}), 5.6 \pm 1.4 \mathrm{kPa}(42.2 \pm 10.7$ $\mathrm{mmHg}$ ), and $\mathrm{pH} 7.39 \pm 0.09$, respectively (Radiometer IIC, Copenhagen).

\section{Experimental protocol}

When steady-state was reached, as indicated by a constant $P$ a and normal blood gas tensions and $\mathrm{pH}$, the experimental protocol was carried out as follows. The ventilator was turned off during expiration and arterial, venous and double occlusions (AO, VO, and DO, respectively) were performed, and the signals were sampled at $200 \mathrm{~Hz}$ and stored in a computer. Arterial occlusion was accomplished using a three-way solenoid valve; venous occlusion was accomplished by rapidly clamping the outflow tubing with a large haemostat; and double occlusion was accomplished by activating the solenoid and clamping the outflow simultaneously. Arterial occlusion lasted for $10 \mathrm{~s}$, while venous and double occlusion lasted 2-4 s. Once this was completed, perfusion was re-established and ventilation of the lobe was switched to a hypoxic gas. Because flow was constant, $P$ a gradually rose during hypoxia, and stabilized after rising an average of $20 \mathrm{mmHg}$. AO, VO and DO were repeated. Flow was re-established to ensure that hypoxic vasoconstriction was maintained. Normoxic ventilation was then re-established and $P$ a returned to baseline value. Angiotensin solution $\left(5 \mu \mathrm{g} \cdot \mathrm{mL}^{-1}\right.$, Sigma Chemical) was then infused continuously at a rate of 0.26 $\mathrm{mL} \cdot \mathrm{min}^{-1}$ into the arterial cannula until the $P$ a rose 5-10 $\mathrm{mmHg}$ and stabilized. Ventilation was turned off in expiration, and AO, DO and VO were performed. Angiotensin infusion was stopped and the $P$ a was allowed to recover.

\section{Data analysis}

The occlusion curves were analysed using two different methods.

Method 1. Arterial, venous, and double occlusion tracings were displayed and analysed independently in the usual manner [1-3, 5]. Figure 1 illustrates such analyses. The arterial occlusion was displayed and analysed (fig. 1a). Briefly, a stretch of data on the arterial pressure between $0.2-2.0 \mathrm{~s}$ following arterial occlusion was fitted to a single exponential and extrapolated back towards time of occlusion. The breakpoint between the rapid and slow phases was then used as a pressure in the small arteries $\left(P^{\prime}\right)$. The double occlusion tracings were then displayed and capillary pressure $\left(P_{\mathrm{c}}\right)$ was determined by averaging the arterial and venous pressures between 2-4 s after the double occlusion (fig. 1b). The venous occlusion tracing was then displayed (fig. 1c), and a stretch of data $(0.2-2.0 \mathrm{~s})$ on the venous
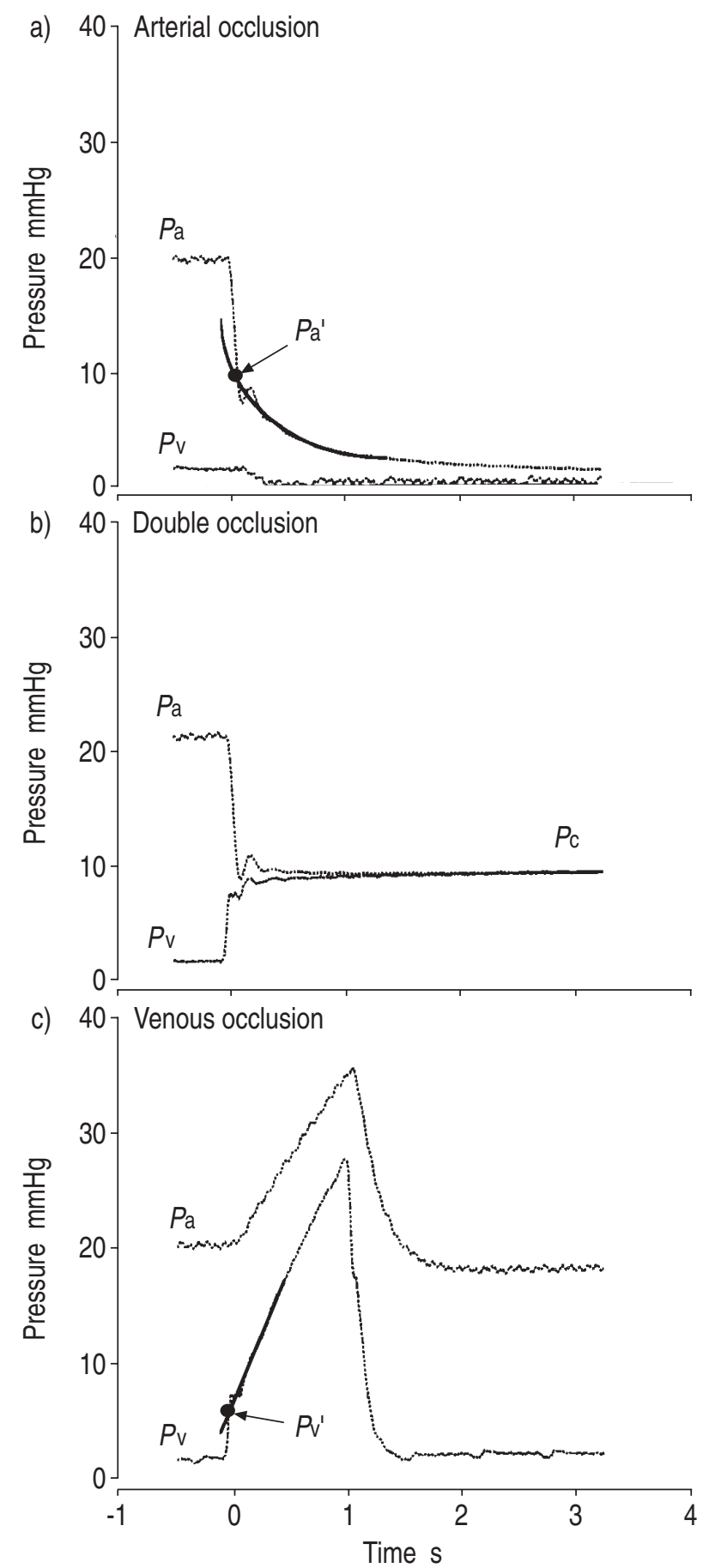

Fig. 1. - Typical examples of the shape of pressure tracings during: a) an arterial occlusion; b) double occlusion; and c) venous occlusion. The method of analysis of each occlusion is illustrated by the thick lines (see text). $P$ a: arterial pressure; $P \mathrm{a}^{\prime}$ : arterial occlusion pressure; $P_{\mathrm{c}}$ : double occlusion pressure (capillary pressure); $P_{\mathrm{v}}$ : venous pressure; $P \mathrm{v}^{\prime}$ : venous occlusion pressure. $(1 \mathrm{mmHg}=0.133 \mathrm{kPa})$. 
pressure was fitted to a straight line and extrapolated back towards time of occlusion. The breakpoint between the rapid and slow phase was used as a pressure in the small veins $\left(P \mathrm{v}^{\prime}\right)$.

Method 2. Alternatively, only the double occlusion tracings were displayed and analysed more thoroughly, as follows (fig. 2). The arterial pressure was first analysed to calculate $P$ a', then the venous pressure was analysed to calculate $P_{\mathrm{v}}$. Because the pressures stabilized quickly during a double occlusion, a shorter stretch of data between $0.2-1.5 \mathrm{~s}$ (instead of $2.0 \mathrm{~s}$ ) was selected and fitted to a monoexponetial. The fitted curve was extrapolated back towards time of occlusion and the breakpoint pressure between the rapid and slow phase was used as $P \mathrm{a}^{\prime}$. Likewise, data between $0.2-1.5 \mathrm{~s}$ on the venous pressure tracing was fitted to an exponential and extrapolated back towards time of occlusion. The breakpoint between the rapid and slow phase was used as $P \mathrm{v}^{\prime}$. The average of $P$ a and $P \mathrm{v}$ between 3-4 s after the occlusion was used, as before, to represent capillary pressure $\left(P_{\mathrm{c}}\right)$.

Although the precise anatomical correlates of these pressures are not known, the evidence in dog [2] and lamb lungs $[6,7]$ suggests that the arterial and venous segments represent vessels larger than $100 \mu \mathrm{m}$ in diameter. The small arterial and venous segments, therefore, represent vessels smaller than $100 \mu \mathrm{m}$ in diameter. Vascular resistance of each of the four segments can be calculated from the pressure gradient of each segment divided by the mean flow rate. For presentation of the data, the mean of each pressure from each method was calculated. A one-way analysis of variance (ANOVA) for repeated measures and a Dunnett t-test were used to determine the significance of changes in each segment under each condition. A paired Student's t-test was used to compare the mean pressures obtained with the two methods of analyses. A p-value of less than 0.05 was considered significant. Agreements between $P \mathrm{a}^{\prime}$ and $P{ }^{\prime}$ derived from the two methods were tested further using two other tests $[8,9]$, as described in the results.

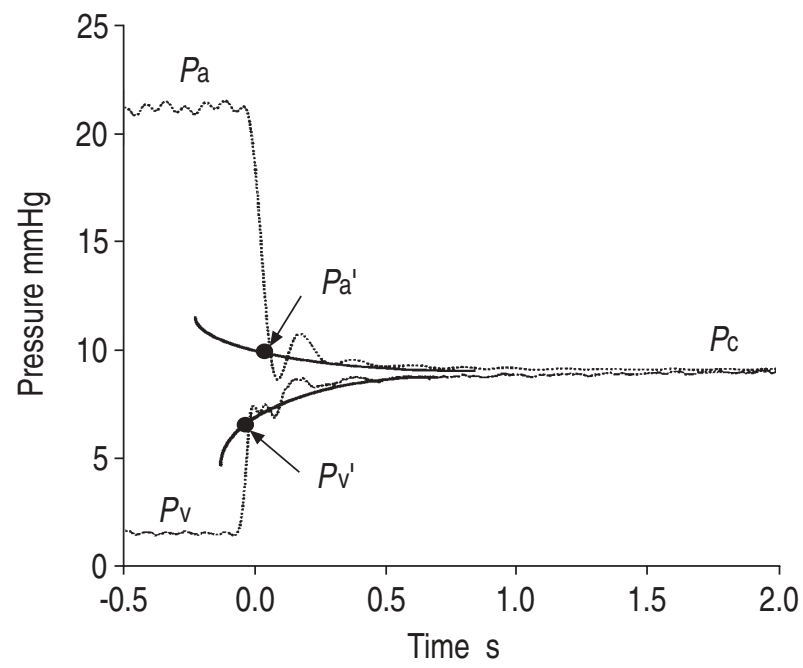

Fig. 2. - Tracings of pressures during a double occlusion (same one as shown in figure 1). Complete analysis of the tracings to derive $P$ a, $P \mathrm{a}^{\prime}, P \mathrm{c}, P \mathrm{v}^{\prime}$, and $P \mathrm{v}$ is illustrated by the thick lines (see text). For definitions see legend to figure 1 . ( $1 \mathrm{mmHg}=0.133 \mathrm{kPa})$.

\section{Results}

Figure 3 illustrates three double occlusions during the $2 \mathrm{~s}$ immediately following the occlusion, for normoxia, hypoxia, and angiotensin infusion. Clearly, both arterial and venous pressures had an initial rapid phase followed by a second slow phase, during which time the two
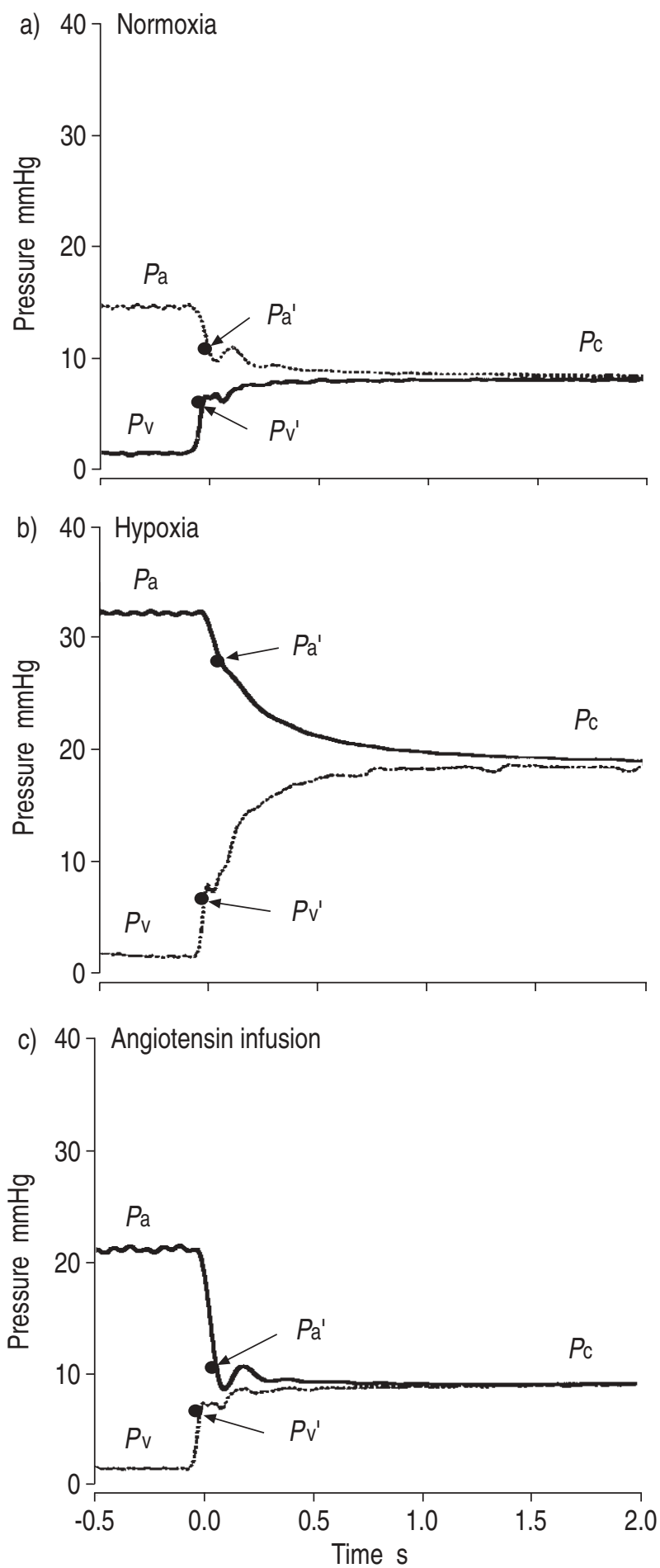

Fig. 3. - Tracings of pressures during double occlusions under three experimental conditions: a) normoxia; b) hypoxia; c) angiotensin infusion. The approximate location of $P \mathrm{a}^{\prime}$ and $P_{\mathrm{v}}$ ' are indicated by a large dot. $P \mathrm{c}$ is the average pressure after equilibration. For definitions see legend to figure 1 . $(1 \mathrm{mmHg}=0.133 \mathrm{kPa})$. 
Table 1. - Mean pressure profiles calculated either from analysis of arterial, venous, and double occlusion tracings (Method 1) or from more thorough analysis of one double occlusion tracing (Method 2)

\begin{tabular}{lcccccc}
\hline & Method & $P \mathrm{a}$ & $P_{\mathrm{a}^{\prime}}$ & $P_{\mathrm{c}}$ & $P_{\mathrm{v}^{\prime}}$ & $P_{\mathrm{v}}$ \\
\hline Normoxia & 1 & $14.2 \pm 1.7$ & $10.8 \pm 1.6$ & $8.9 \pm 1.9$ & $7.3 \pm 1.5$ & $1.3 \pm 0.6$ \\
\multirow{3}{*}{ Hypoxia } & 2 & $14.7 \pm 2.1$ & $11.0 \pm 2.2$ & $8.9 \pm 1.9$ & $7.3 \pm 1.3$ & $1.3 \pm 0.6$ \\
\multirow{2}{*}{ Angiotensin } & 1 & $31.8 \pm 6.4$ & $27.0 \pm 5.8$ & $17.7 \pm 4.3$ & $9.8 \pm 4.1$ & $1.3 \pm 0.6$ \\
& 2 & $32.2 \pm 5.7$ & $27.2 \pm 5.7$ & $17.7 \pm 4.3$ & $9.6 \pm 3.4$ & $1.3 \pm 0.6$ \\
& 1 & $23.3 \pm 4.4$ & $13.1 \pm 5.2$ & $11.3 \pm 2.6$ & $8.8 \pm 2.7$ & $1.4 \pm 0.5$ \\
& 2 & $24.2 \pm 5.0$ & $14.9 \pm 5.9$ & $11.3 \pm 2.6$ & $9.2 \pm 2.0$ & $1.4 \pm 0.5$ \\
\hline
\end{tabular}

The values are presented as mean \pm SD from 10 animals. $P$ a: arterial pressure; $P$ a': arterial occlusion pressure; $P_{\mathrm{c}}$ : double occlusion pressure (capillary pressure); $P_{\mathrm{v}}$ : venous occlusion pressure; $P$ v: venous pressure. Mean flow rate in the 10 animals was $493 \pm 60 \mathrm{~mL} \cdot \mathrm{min}^{-1}$. There was no difference between values calculated from the two methods.

pressures equilibrate with capillary pressure. The shape of the curves are more visible during hypoxia, when the resistance of the small vessels is elevated. The two methods of analysis were used to analyse the occlusion tracings under all three conditions. Table 1 shows the mean data for each condition. The first line for each condition represents the mean pressure values obtained with Method 1, as described previously [1-3, 6, 10-13]; $P \mathrm{a}^{\prime}$ was obtained from an arterial occlusion, $P_{\mathrm{c}}$ was obtained from a double occlusion, and $P_{\mathrm{v}^{\prime}}$ was obtained from a venous occlusion. $P$ a and $P$ v were averaged from the three values prior to each occlusion manoeuvre. The five values, $P \mathrm{a}, P \mathrm{a}^{\prime}, P \mathrm{c}, P_{\mathrm{v}}{ }^{\prime}$, and $P_{\mathrm{v}}$, which were derived from three occlusion manoeuvres, were then combined into one pressure profile.

The second line for each condition in table 1 presents the mean data from Method 2, whereby all five pressures, $P$ a, $P$ a',$P$ c,$P v^{\prime}$, and $P$ v, were obtained from a single double occlusion manoeuvre. The agreement between the two methods was tested in three different ways. Firstly, the mean values of each pressure with the two methods were compared using a simple Student's t-test. There was no significant difference between the mean values for $P \mathrm{a}, P \mathrm{a}^{\prime}, P \mathrm{c}, P \mathrm{v}^{\prime}$, and $P \mathrm{v}$ derived using the two methods under all conditions.

The agreement between the two methods was further tested by using regression analysis. A scattergram of all data points for $P^{\prime}$ and $P \mathrm{v}^{\prime}$ from the two methods is

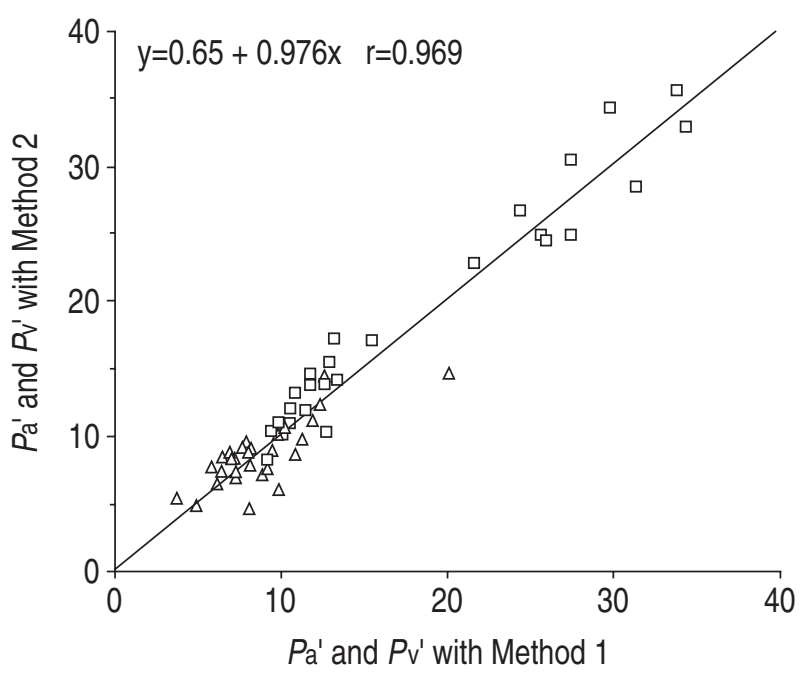

Fig. 4. - Relationship of $P \mathrm{a}^{\prime}(\square)$ and $P_{\mathrm{v}^{\prime}}(\Delta)$ from the two methods. The line of identity is drawn. The equation for linear regression is also shown. For definitions see legend to figure 1. shown in figure 4. All the data points fell close to the line of identity. The slope of linear regression was 0.957 , with a $95 \%$ confidence interval of $0.960-0.976$, based on Fisher's z-transformation analysis [8]. The regression analysis suggested an excellent agreement between the two methods.

Finally, the limits of agreement between the two methods were tested according to the analysis of BLAND and Altman [9]. The difference between the $P \mathrm{a}^{\prime}$ or $P \mathrm{v}^{\prime}$
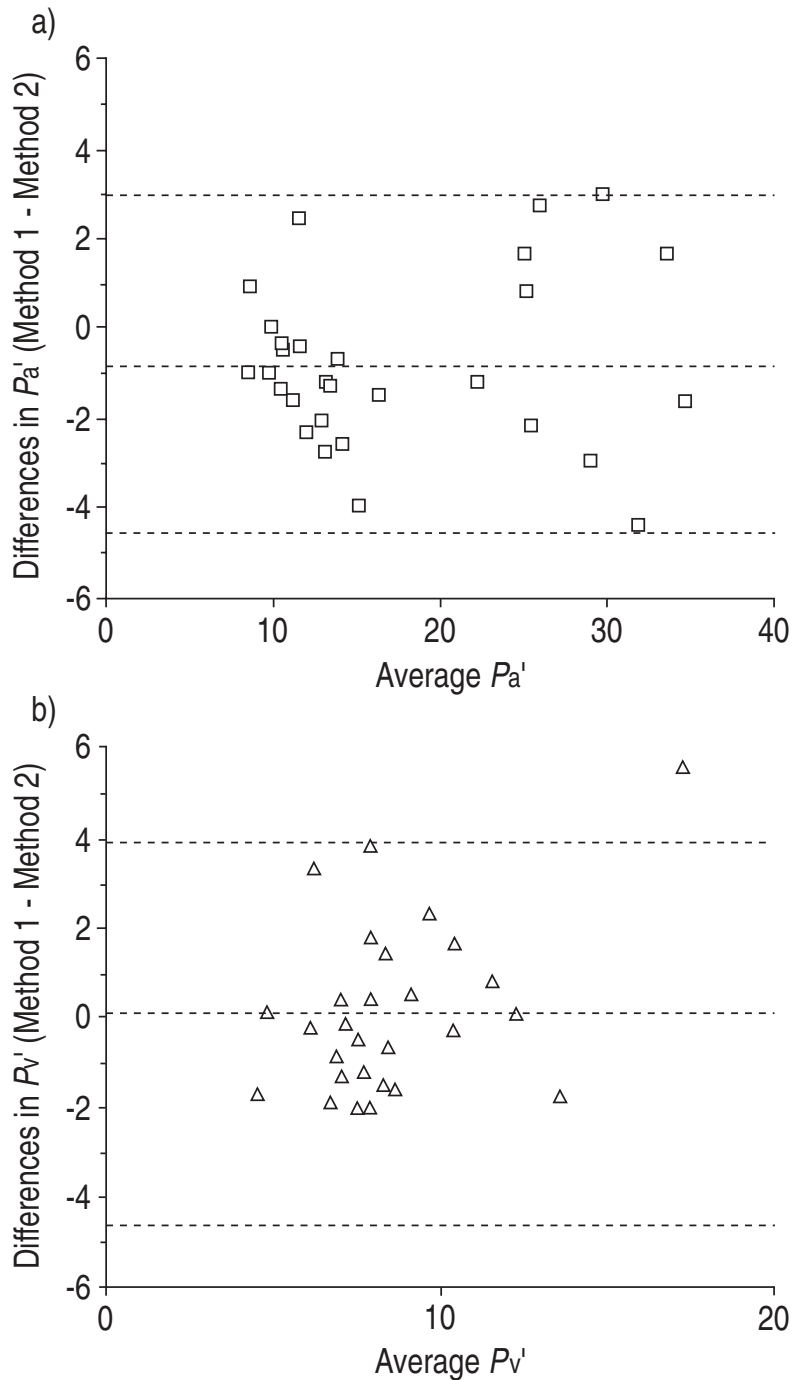

Fig. 5. - Difference in a) $P \mathrm{a}^{\prime}$ and b) $P \mathrm{v}^{\prime}$ between the two methods against the average of the two methods. The mean difference $\pm 2 \mathrm{SD}$ is indicated by the dotted lines. For definitions see legend to figure 1 . 
values from the two methods was plotted against the average of the two methods (fig. 5). The figure indicates that the mean difference is not significantly different from zero and that all differences fell within \pm 2 SD. An estimate of reliability of agreement (intraclass regression) between the two methods was calculated from mean squares among $(\mathrm{Ma})$ and within $\left(\mathrm{Mw}_{\mathrm{w}}\right.$ the values, $(\mathrm{Ma}-\mathrm{Mw}) /(\mathrm{Ma}+\mathrm{Mw})$ [8]. An estimate of 1 suggests perfect agreement, and 0 suggests no agreement between the two methods. Estimate of reliability for $P \mathrm{a}^{\prime}$ was 0.97 and for $P_{\mathrm{v}}{ }^{\prime}$ was 0.78 . This test further supports the excellent agreement between the two methods.

\section{Discussion}

The method of analysis of arterial and venous occlusion tracings and the anatomical correlates of the arterial, venous and middle segment has been the subject of other papers by our group and by others $[1,6,7,13$, 14]. Analysis of the double occlusion has been less controversial. The validity of pressures derived using the occlusion technique was verified by comparing the occlusion measurements with direct measurements using small catheters or by micropuncture [2,6]. Criteria of the analysis, and the influence of small variations in the number of data points and the selection of time zero has also been discussed previously [1]. This study uses such published analytical criteria, and presents new information which can be derived from the double occlusion. The double occlusion is a simultaneous arterial and venous occlusion, and the shape of the arterial and venous pressure tracings appear very similar to those recorded during a single arterial and a single venous occlusion. Therefore, it occurred to us that the analysis which is used for arterial and venous occlusion could also be applied to the tracings during a double occlusion. The purpose of this study was, therefore, to determine whether the pressures which are derived from the arterial and venous occlusion can also be derived from a double occlusion.

The results show that, indeed, one double occlusion can be analysed more thoroughly to partition the pulmonary vasculature into four segments. The pressures derived from analysis of one double occlusion were not significantly different from those obtained from analyses of arterial, double, and venous occlusions. Therefore, the double occlusion can differentiate not only whether the site of resistance is upstream or downstream from a mid-capillary point, but with this thorough analysis it provides information about whether the resistance had changed in the large or in the small vessels. The data from previous studies suggest that $P_{\mathrm{a}}{ }^{\prime}$ and $P \mathrm{v}^{\prime}$ represent pressures in arteries and veins $<0.1 \mathrm{~mm}$ in diameter [2, $6,7]$. Thus, the occlusion technique partitions resistance into four segments: large arteries $(>0.1 \mathrm{~mm}$ in diameter); small arteries $(<0.1 \mathrm{~mm})$; small veins $(<0.1 \mathrm{~mm})$; and large veins $(>0.1 \mathrm{~mm})$. The increase in resistance in the small vessels can be due to vasoconstriction, or due to mechanical factors, such as an increase in alveolar pressure or an increase in blood viscosity [2, 12].

The results of the present study are consistent with previous findings, namely that hypoxia increases the resistance of the small vessels, while vasoactive agents increased the resistance of the large vessels [5]. The hypoxic response in these animals was much larger than in a previous study because the animals were pretreated with indomethacin to enhance the hypoxic vasoconstriction $[10,15]$. Addition of indomethacin to the blood, however, had caused an increase in venous resistance during baseline conditions, as reported previously [16]. Therefore, the relative contribution of the venous resistance in this study was larger than previously reported by us in the same animal preparation.

The two methods for partitioning of pulmonary vascular resistance into four segments agreed strongly with each other. Partitioning of the resistance into four segments from one double occlusion with Method 2 has some advantages. One obvious advantage is time-saving during the experiment, since only one occlusion is necessary instead of three. More importantly, however, if the pulmonary arterial pressure is not stable, the double occlusion analysis is very suitable. When three occlusions are being utilized, it is necessary to wait for the pressure to return to a steady value before the next occlusion can be performed. This can create problems because vascular constriction is not always perfectly stable. The lack of stability may lead to measurement of a capillary pressure that is larger or smaller than the $P \mathrm{a}^{\prime}$ or $P \mathrm{v}^{\prime}$, respectively. This problem is totally eliminated if one utilizes one double occlusion to derive all five pressures. Lack of a stable $P$ a becomes a problem, in particular, if one is evaluating a transient response, such as during injection of drugs as a bolus, whereby the pressure rises and falls without stabilizing. Under such conditions, the double occlusion is useful and can be performed at any point during the transient response.

Conceptually, there may be an advantage in analysing the double occlusion as described in Method 2. While a shorter segment of data becomes available for the analysis, such segments may provide more accurate data because the shape of the arterial and venous pressures are determined primarily by the upstream and downstream segments, respectively. Thus, the shape of the arterial pressure during a double occlusion may be more reflective of the arterial tree, while the shape of the venous pressure may be more reflective of the venous tree, because the two pressures equilibrate with capillary pressure. Consequently, calculation of $P \mathrm{a}^{\prime}$ and $P_{\mathrm{v}}{ }^{\prime}$ may be more accurate or, at worst, not significantly different from values obtained from an arterial and a venous occlusion.

One disadvantage of Method 2 is the shorter segments of data which are recorded before the pressure reaches a steady-state. This may conceal the shape of the pressure curves and may make them more difficult to analyse. This problem can be resolved by recording the pressure on an expanded scale, so that the shape of the curve remains visible. Acquisition of data using a computer is also helpful in this regard. Although we performed exponential fitting to the curves, in many instances it would have been possible to fit a straight line to the data in order to extrapolate back to time zero.

In summary, we found that the double occlusion can be analysed more thoroughly to partition the pulmonary vasculature into four segments, thus providing more information than previously suggested. 


\section{References}

1. Hakim TS. Criteria for analysis of the arterial and venous occlusion. J Appl Physiol 1991; 70: 665-675.

2. Hakim TS, Kelly SM. Occlusion pressures vs micropipette pressures in the pulmonary circulation. J Appl Physiol 1989; 67: 1277-1285.

3. Hakim TS, Michel RP, Minami H, Chang HK. Site of pulmonary hypoxic vasoconstriction studied with arterial and venous occlusion. J Appl Physiol: Respirat Environ Exercise Physiol 1983; 54: 1298-1302.

4. Dawson CA, Linehan JA, Rickaby DA. Pulmonary microcirculatory hemodynamics. Ann NY Acad Sci 1982; 384: 90-106.

5. Hakim TS. Vasoconstriction in large and small vessels in isolated canine lungs. Respiration 1988; 54: 61-69.

6. Fike CD, Gordon JB, Kaplowitz MR. Micropipette and vascular occlusion pressures in isolated lungs of newborn lambs. J Appl Physiol 1993; 75: 1854-1869.

7. Michel RP, Gordon JB, Chu K. Development of the pulmonary vasculature in newborn lambs: structurefunction relationship. J Appl Physiol 1991; 70: 12551264

8. Zar JH. Biostatistical Analysis. Second edition. Englewood Cliffs, NJ, Princeton-Hall Inc., 1984; pp. 311-425.

9. Bland JM, Altman DG. Statistical methods for assess- ing agreement between two methods of clinical measurement. Lancet 1986; i: 307-310.

10. Gordon JB, Hortop J, Hakim TS. Developmental effects of hypoxia and indomethacin on distribution of vascular resistances in lamb lungs. Ped Res 1989; 26: 325-329.

11. Gordon JB, Tod ML. Effects of N $\omega$-nitro-L-arginine on total and segmental vascular resistances in developing lamb lungs. J Appl Physiol 1993; 75: 76-85.

12. Julien M, Hakim TS, Vahi R, Chang HK. Effect of hematocrit on vascular pressure profile in dog lungs. $J$ Appl Physiol 1985; 58: 743-748.

13. Rock P, Patterson A, Permutt S, Sylvester J. Nature and distribution of vascular resistance in hypoxic pig lungs. J Appl Physiol 1985; 59: 1891-1901.

14. Baconnier PF, Eberhard A, Grimbert FA. Theoretical analysis of occlusion techniques for measuring pulmonary capillary pressure. J Appl Physiol 1992; 73: 13511359.

15. Hales CA, Rouse ET, Slate JL. Influence of aspirin and indomethacin on variability of alveolar hypoxic vasoconstriction. J Appl Physiol: Respirat Environ Exercise Physiol 1978; 45: 33-39.

16. Endredi J, El-Kashef HA, Hofman WF, Ehrhart IC. Effects of different cyclo-oxygenase inhibitors on the segmental distribution of pulmonary vascular resistance in the dog. Pharmacology 1992; 44: 306-314. 